\title{
Novel Macrocyclic Peptides Active at Human Melanocortin Receptors: A Preliminary SAR Study
}

\author{
A.M. Yousif ${ }^{1}$, M. Cai ${ }^{2}$, F. Merlino ${ }^{1}$, P. Grieco' ${ }^{1}$, and V.J. Hruby ${ }^{2}$ \\ ${ }^{1}$ Dept. of Pharmacy, University of Naples "Federico II", Naples, Italy; \\ ${ }^{2}$ Dept. of Chemistry, University of Arizona, Tucson, AZ, USA
}

\section{Introduction}

The melanocortins are a group of structurally related peptides derived from proopiomelanocortin (POMC), their name from their melanotropic and corticotropic activities and are comprised of adrenocorticotropic hormone $(\mathrm{ACTH}), \alpha$-melanocyte stimulating hormone $(\alpha-\mathrm{MSH}), \beta$-MSH, and $\gamma$-MSH. The effects of melanocortins are mediated by activation of a family of melanocortin receptors (MCRs). Five MCR (MC1R, MC2R, MC3R, MC4R, and MC5R) (Figure 2) genes have been cloned and the receptors pharmacologically characterized [1]. All the melanocortin ligands conserve the core sequence, Trp-Arg-Phe-His. Previous SAR study on melanotropins, in particular on $\alpha$-MSH, led to the small cyclic peptide MT-II, a potent and non-selective agonist at MCRs.
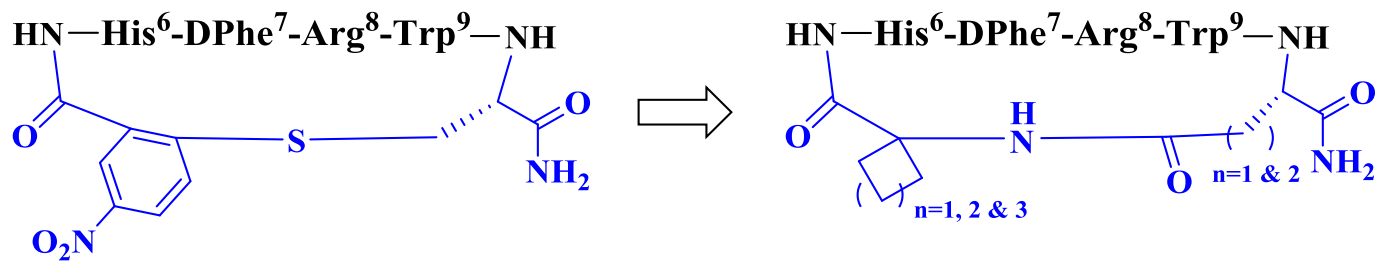

Fig. 1. New cyclic lactam peptide analogues of $\alpha$-MSH containing $\alpha, \alpha$-disubstituted amino acids.

Similarly, the lactam analogue, SHU-9119, is an antagonist at MCRs 3 and 4 receptors. Subsequently, we developed a series of novel 20-membered macrocycles formally derived from MTII and SHU9119, containing an alkylthioaryl bridge. Based on these considerations, herein we synthesized a new cyclic lactam peptide analogues of $\alpha$-MSH containing $\alpha, \alpha$-disubstituted amino acids to provide further SAR study.

\section{Design, Synthesis and Peptide Library}

The cyclization approach by disulphide bond, and lactam on melanocortins led to interesting results. Previously, our research group has developed melanocortin peptide analogues in which 2-fluoro-5-nitro benzoic acid was used for the macrocyclization reaction, side chain to tail cyclization (Figure 1) [2]. Among these compounds, PG10N, represents a potent analogue which has different conformation compared with MTII and shown to be selective for the MC5R. In the present study, we synthesized a new 18 lactam macrocyclic analogues of $\alpha$-MSH by the introduction of $\alpha, \alpha$-disubstituted amino acids such as Fmoc-1-

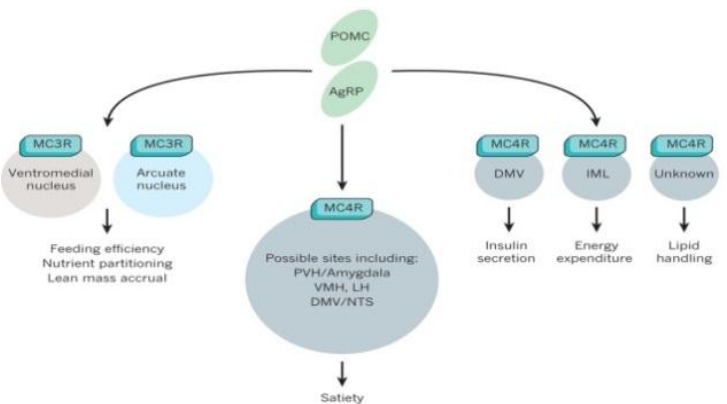

Fig. 2. Melanocortin receptors and their functions.

amino-1-cyclopentane carboxylic acid, and Fmoc-1-amino-1-cycloexane carboxylic acid. Furthermore, we investigated the role of the ring dimension on the biological activity by the replacement of Asp residue with Glu turning from 19-membered macrocyclic ring to 20-membered ring (Table 1). 


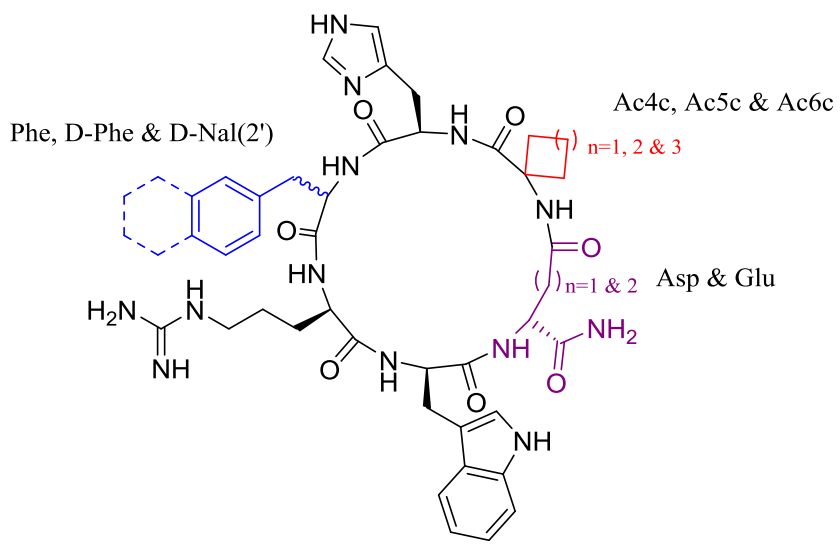

Table 1. Macrocyclic peptide library.

\begin{tabular}{|c|c|}
\hline Peptide & Sequence \\
\hline 1 & [Ac4c-His-Phe-Arg-Trp-Asp]- $\mathrm{NH}_{2}$ \\
\hline 2 & [Ac5c-His-Phe-Arg-Trp-Asp]-NH ${ }_{2}$ \\
\hline 3 & [Ac6c-His-Phe-Arg-Trp-Asp]- $\mathrm{NH}_{2}$ \\
\hline 4 & [Ac4c-His-Nal(2')-Arg-Trp-Asp]-NH ${ }_{2}$ \\
\hline 5 & [Ac5c-His-Nal(2')-Arg-Trp-Asp]-NH ${ }_{2}$ \\
\hline 6 & [Ac6c-His-Nal(2')-Arg-Trp-Asp]-NH ${ }_{2}$ \\
\hline 7 & [Ac4c-His-D-Phe-Arg-Trp-Asp]-NH ${ }_{2}$ \\
\hline 8 & [Ac5c-His-D-Phe-Arg-Trp-Asp]-NH ${ }_{2}$ \\
\hline 9 & [Ac6c-His-D-Phe-Arg-Trp-Asp]-NH ${ }_{2}$ \\
\hline 10 & [Ac4c-His-D-Nal(2')-Arg-Trp-Asp]-NH \\
\hline 11 & [Ac5c-His-D-Nal(2')-Arg-Trp-Asp]- $\mathrm{NH}_{2}$ \\
\hline 12 & [Ac6c-His-D-Nal(2')-Arg-Trp-Asp]- $\mathrm{NH}_{2}$ \\
\hline 13 & [Ac4c-His-D-Phe-Arg-Trp-Glu]-NH 2 \\
\hline 14 & [Ac5c-His-D-Phe-Arg-Trp-Glu]- $\mathrm{NH}_{2}$ \\
\hline 15 & [Ac6c-His-D-Phe-Arg-Trp-Glu]- $\mathrm{NH}_{2}$ \\
\hline 16 & [Ac4c-His-D-Nal(2')-Arg-Trp-Glu]- $\mathrm{NH}_{2}$ \\
\hline 17 & [Ac5c-His-D-Nal(2')-Arg-Trp-Glu]-NH \\
\hline 18 & [Ac6c-His-D-Nal(2')-Arg-Trp-Glu]- $\mathrm{NH}_{2}$ \\
\hline
\end{tabular}

The synthesis was accomplished using Fmoc chemistry in solid phase. The first coupling was carried out using Fmoc-Xaa(OAll)-OH (Xaa: Asp or Glu), activating groups, in presence of Hunig's base in DMF for 2 hours. After the elongation of peptide on resin by standard solid phase synthesis. The allyl protecting group was removed by treating the resin with tetrakis(triphenylphosphine)-palladium (0) and $N, N$ 'dimethylbarbituric acid in DCM/DMF under nitrogen atmosphere for 2 hours and the procedure was repeat again. The side chain to tail cyclization was carried out directly on solid support using HBTU as and Hunig's base for 12 hours. The peptide was released using a cocktail of TFA/TIS/ $\mathrm{H}_{2} \mathrm{O}(95: 2.5: 2.5, \mathrm{v} / \mathrm{v} / \mathrm{v})$ for 3 hours. All crude peptides were purified by RP-HPLC and the final products were characterized by LCMS (Scheme 1).

\section{Results and Discussion}

In this study we prepared a number of cyclic melanotropin analogues in which an $\alpha, \alpha$-disubstituted amino acids was used for the macrocyclization reaction. These compounds conserve the core sequence His-Phe-Arg-Trp which is responsible for the biological activities. All synthesized compounds were evaluated for their binding affinities at human melanocortin receptors in competitive binding assays for their potency in cAMP assays employing the HEK293 cells expressing the receptors. The results are reported in Table 2.

In conclusion, we have designed and synthesized new macrocyclic melanocortin ligands. The introduction of an $\alpha, \alpha$-disubstituted amino acids instead of 2-fluoro-5-nitro benzoic acid could be determinant to get additional selective compounds at hMCRs. In this study, we evaluated the role of ring dimension in binding activity, turning form 19- to 20- membered ring dimension. In fact, the preliminary biological data showed that the ring dimension could have a key role on biological activity also in these series of compounds. 


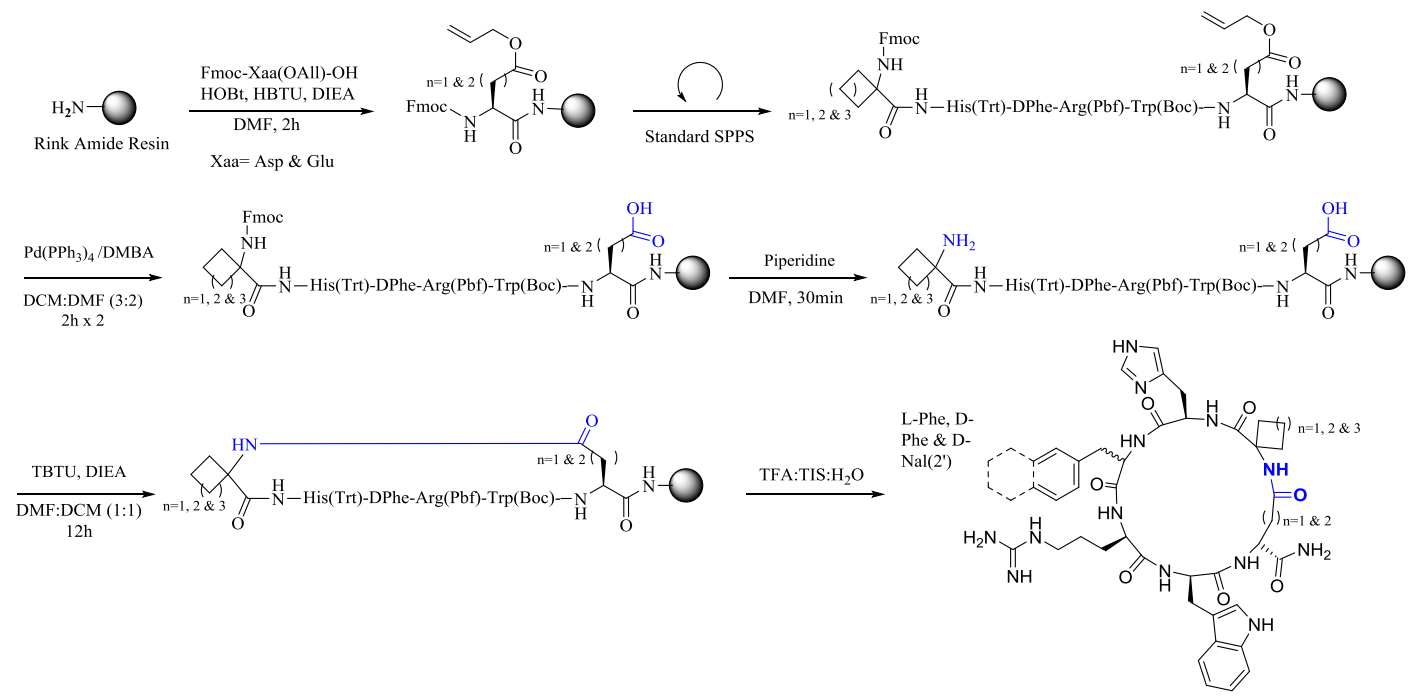

Scheme 1. The synthesis was accomplished using Fmoc chemistry in solid phase.

Table 2. Biological results.

\begin{tabular}{|c|c|c|c|c|c|c|c|c|c|c|c|c|}
\hline \multicolumn{4}{|c|}{ hMC1R } & \multicolumn{3}{|c|}{ hMC3R } & \multicolumn{3}{|c|}{ hMC4R } & \multicolumn{3}{|c|}{ hMC5R } \\
\hline & \multirow{2}{*}{$\frac{\text { Binding }}{\mathrm{IC}_{50}(\mathrm{nM})}$} & \multicolumn{2}{|c|}{ cAMP } & \multirow{2}{*}{$\begin{array}{l}\text { Binding } \\
\mathrm{IC}_{50}(\mathrm{nM})\end{array}$} & \multicolumn{2}{|c|}{ cAMP } & \multirow{2}{*}{$\begin{array}{l}\text { Binding } \\
\qquad \mathrm{IC}_{50}(\mathrm{nM})\end{array}$} & \multicolumn{2}{|c|}{ cAMP } & \multirow{2}{*}{$\begin{array}{l}\text { Binding } \\
\mathrm{IC}_{50}(\mathrm{nM})\end{array}$} & \multirow{2}{*}{$\frac{\mathrm{cAMP}}{\mathrm{EC}_{50}(\mathrm{nM})}$} & \multirow[b]{2}{*}{ Act $\%$} \\
\hline & & EC50 (nM) & Act $\%$ & & $\mathrm{EC}_{50}(\mathrm{nM})$ & Act $\%$ & & $\mathrm{EC}_{50}(\mathrm{nM})$ & Act $\%$ & & & \\
\hline 1 & 39.12 & 370 & $>100$ & NB & $>10000$ & $>100$ & 2380 & 217 & $>100$ & 2.21 & 0.1 & 30 \\
\hline 2 & 5.71 & 43.16 & 16.8 & NB & NA & -20.9 & 1454 & NA & 30 & 1.93 & $<0.01$ & 14.5 \\
\hline 3 & 1748 & 60.89 & 28.5 & NB & NA & 12.5 & $<0.01$ & NA & 35.1 & 17.43 & 3.02 & 58 \\
\hline 4 & 22.89 & 0.4632 & 24 & NB & NA & -21.7 & $>10000$ & $\mathrm{NA}$ & 43.3 & 1.82 & $<0.01$ & 65.9 \\
\hline 5 & 1.063 & 226.1 & 80 & 919.9 & NA & -14.8 & 39.1 & NA & 13.9 & NB & $<0.01$ & 72.5 \\
\hline 6 & $>10000$ & 1.223 & 33.1 & NB & NA & -20.6 & 2584 & 3977 & 19.6 & 0.54 & 0.55 & 82.9 \\
\hline 8 & $4906 \pm 400$ & 17 & 100 & 279 & 5.1 & 100 & 1902 & 311 & 100 & NB & NA & 0 \\
\hline 9 & $2744 \pm 104$ & 12 & 100 & 234 & 23.4 & 100 & 836 & 122 & 96 & NB & NA & 0 \\
\hline 10 & $1256 \pm 97$ & 25 & 100 & $100 \pm 6$ & 3.4 & 50 & 783 & 331 & 70 & $>10000$ & 1536 & 100 \\
\hline 11 & $3303 \pm 297$ & 13 & 100 & 61 & 3.3 & 68 & 590 & 0.52 & 67 & 1374 & 214 & 100 \\
\hline 12 & $1583 \pm 174$ & 11 & 100 & 23 & 12.5 & 91 & 449 & 3.4 & 67 & $>10000$ & 182 & 100 \\
\hline 14 & $1036 \pm 63$ & 3.9 & 100 & $1173 \pm 148$ & 0.93 & 100 & 1274 & 372 & 100 & NB & NA & 0 \\
\hline 17 & $3140 \pm 414$ & 3.4 & 100 & $24 \pm 3$ & 8.5 & 82 & 1126 & 669 & 74 & $>10000$ & 47 & 100 \\
\hline
\end{tabular}

\section{References}

1. Grieco, P., Han, G., Weinberg, D., Van der Ploeg, L.H., Hruby, V.J. Biochem. Biophys. Res. Commun. 292, 1075-1080 (2002), http://dx.doi.org/10.1006/bbrc.2002.6739

2. Grieco, P., Cai, M., Liu, L., Mayorov, A., Chandler, K., Trivedi, D., Lin, G., Campiglia, P., Novellino, E., Hruby, V.J. J. Med. Chem. 51, 2701-2707 (2008), http://dx.doi.org/10.1021/jm701181n 